\title{
Leptomeningeal Disease from Oligodendroglioma: Clinical and Molecular Analysis
}

\author{
Gloria Roldán, James Scott, David George, Ian Parney, Jacob Easaw, \\ Gregory Cairncross, Peter Forsyth*, Elizabeth Yan
}

\begin{abstract}
Background: Leptomeningeal disease (LMD) is a late complication of malignant glioma, mostly of glioblastoma, that usually responds poorly to treatment and is rapidly fatal. A long surviving case led us to review our experience with LMD in patients with oligodendrogliomas. Methods: A 15-year retrospective chart review was performed. Patients with both oligodendroglial tumors and LMD were identified. A single neuro-pathologist reviewed all histological sections, a single neuro-radiologist reviewed all available images and 1p/19q status was assessed. Results: Seven out of 145 patients with oligodendroglioma were diagnosed with LMD. Six were male. Median age at tumor diagnosis was 41 years (range, 28-50). None had radiographic or pathological evidence of leptomeningeal or subependymal tumor at initial diagnosis. Most patients had pure anaplastic oligodendrogliomas (4/7); 6/7 had 1p/19q co-deletion. The median time to first relapse was 41 months (range, 19-127). The median time to LMD was 76 months (range, 19-151) from initial diagnosis and 28 months (range, 0-36) from first relapse, respectively. Leptomeningeal disease treatments included spinal radiation and intrathecal and systemic chemotherapy. After progression, some patients with LMD remained stable clinically. The median survival from initial diagnosis was 104 months (range, 19-183) and from LMD diagnosis was 32 months (range, 2-43). Conclusions: Leptomeningeal disease is a complication of oligodendroglioma that may occur preferentially in long surviving patients with $1 \mathrm{p} / 19 \mathrm{q}$ codeletion. Leptomeningeal disease in patients with oligodendrogliomas appears to be relatively indolent which may have implications for their treatment and be related to $1 \mathrm{p} / 19 \mathrm{q}$ status.
\end{abstract}

RÉSUMÉ: Envahissement des leptoméninges par un oligodendrogliome : analyse clinique et moléculaire. Contexte : Une atteinte des leptoméninges (ALM) est une complication tardive du gliome malin, surtout du glioblastome, qui répond habituellement peu au traitement et qui est rapidement fatale. L'observation d'un patient dont la survie a été longue nous a amenés à réviser notre expérience concernant l'ALM chez des patients porteurs d'un oligodendrogliome. Méthodes : Nous avons procédé à une revue rétrospective de dossiers sur une période de 15 ans. Les patients atteints de tumeurs oligodendrogliales et d'ALM ont été identifiés. Un seul neuropathologiste a révisé toutes les coupes histologiques et un seul neuroradiologiste a revu toute l'imagerie. Le statut $1 \mathrm{p} / 19 \mathrm{q}$ a été déterminé. Résultats : Un diagnostic d'ALM a été posé chez 7 des 145 patients porteurs d'un oligodendrogliome. Six de ces 7 patients étaient des hommes. L'âge médian au moment du diagnostic de la tumeur était de 41 ans (écart de 28 à 50 ans). Aucun n'avait de signes radiologiques ou anatomopathologiques d'envahissement des leptoméninges ou d'envahissement sous-épendymaire au moment où le diagnostic initial a été posé. La plupart des patients étaient porteurs d'oligodendrogliomes anaplasiques pures (4/7); 6/7 avaient une co-délétion 1p/19q. Le temps médian du traitement initial jusqu'à la première rechute était de 41 mois (écart de 19 à 127 mois). Le temps médian du diagnostic initial et de la première rechute jusqu'à l'ALM était de 76 mois (écart de 19 à 151 mois) et de 28 mois (écart de 0 à 36 mois) respectivement. Les patients ayant une ALM ont été traités par irradiation spinale et chimiothérapie intrathécale et systémique. Certains patients ayant une ALM sont demeurés stables au point de vue clinique. La survie médiane à partir du moment du diagnostic initial était de 104 mois (écart de 19 à 183 mois) et à partir du moment du diagnostic d'ALM elle était de 32 mois (écart de 2 à 43 mois). Conclusions : L'ALM est une complication de l'oligodendrogliome qu'on rencontre surtout chez les patients dont la survie est longue et qui sont porteurs d'une co-délétion 1p/19q. L'ALM chez les patients atteints d'oligodendrogliome semble relativement indolente ce qui peut avoir des implications pour le traitement et être relié au statut 1p/19q.

Can. J. Neurol. Sci. 2008; 35: 204-209

Leptomeningeal disease (LMD), also known as leptomeningeal metastasis or meningeal gliomatosis, is an infrequent, late and rapidly fatal complication of malignant glioma, especially of glioblastoma multiforme (GBM). Leptomeningeal spread has been reported to occur in up to $7 \%$ of patients with GBM, and in a recent study of patients with highgrade astrocytomas and LMD, median survival was only four months (15 days-11months). ${ }^{1,2}$ Leptomeningeal metastasis is seldom a clinical concern at initial diagnosis, but instead, is usually encountered at the time of intracerebral recurrence, often
From the Department of Oncology, Tom Baker Cancer Centre, Alberta Cancer Board (GR, IP, JE, PF, GC, EY); Department of Clinical Neurosciences (GR, JS, IP, PF, GC), Department of Diagnostic Imaging (JS), Department of Pathology \& Lab Medicine (DG), University of Calgary; Clark Smith Integrated Brain Tumor Research Centre (GR, IP, JE, PF, GC, EY), Calgary, Alberta, Canada.

Received April 5, 2007. Final Revisions Submitted November 8, 2007. Corresponding Author*: Peter Forsyth, Clark Smith Brain Tumor Center, Rm. 2AA19 Health Research Innovation Center, 3330 Hospital Drive NW, Calgary, Alberta, T2N 4N1, Canada. 
in a patient who responded to initial treatment. Occasionally, LMD is the only site of relapse. Such cases of isolated leptomeningeal recurrence are difficult to diagnose because clinical deterioration may be subtle, or in the first instance, unaccompanied by neuro-imaging changes. Eventually, however, cognitive deterioration, headache, imbalance, cranial neuropathy, back pain, leg weakness, bowel and bladder disturbance, or other symptoms and signs of a leptomeningeal disturbance appear and are accompanied by abnormal findings on gadolinium-enhanced magnetic resonance imaging (MRI) of the head and spine, either communicating hydrocephalus, diffuse leptomeningeal enhancement, or multiple spinal nodules. It was in this context that we encountered a patient with leptomeningeal oligodendroglioma whose clinical course was extraordinarily indolent. This long-surviving case prompted us to review the clinical course and molecular genetic features of patients at the University of Calgary who developed LMD in association with an oligodendroglioma.

\section{Patients and Methods}

Patients at the Tom Baker Cancer Centre (Calgary, Alberta, CANADA) with oligodendroglial tumors who were diagnosed with LMD between January 1997 and December 2006 were identified by chart review. The criteria for diagnosis of LMD were established in advance of the chart review and were as follows: any two of 1) neurological symptoms or signs consistent with LMD, 2) MRI changes consistent with LMD (subependymal or subarachnoid spread), or 3) cerebrospinal fluid (CSF) cytological alterations consistent with leptomeningeal gliomatosis. All cases whose eligibility was based in part on imaging criteria were reviewed by single neuroradiologist (J.N.S.). All cases deemed eligible were also reviewed by a single neuropathologist (D.G.). The histological diagnosis of the primary tumor was based on the World Health Organization (WHO) classification of oligodendroglioma (i.e., oligodendroglioma or mixed oligoastrocytoma) and tumor grading was performed as described by Giannini et al. ${ }^{3}$ In addition, the status of chromosomes $1 p$ and $19 q$ was evaluated in the primary tumor by either polymerase chain reaction (PCR) or fluorescent in situ hybridization (FISH) techniques as described elsewhere. Information extracted from each patient's health record included clinical and pathological features, details of initial treatment and clinical course. The Tom Baker Cancer Centre is the sole provider of cancer treatment services for the 1.5 million residents of Southern Alberta. Approval to conduct this retrospective study was obtained from the Conjoint Health Research Ethics Board of the University of Calgary.

\section{Results}

From January 1997 to December 2006, seven patients with oligodendrogliomas developed LMD. Their primary oligodendroglial tumor was diagnosed between July 1991 and October 2004. During this 15 year interval, 145 oligodendrogliomas were diagnosed; LMD developed in 7 of 145 $(4.8 \%)$.

Initial diagnosis and first recurrence: There was no clinical or radiographic evidence of LMD or subependymal spread at initial diagnosis of the primary tumor in any patient who subsequently developed meningeal gliomatosis. In one case, the tumor was superficially located, abutting the pial surface of the brain. The primary tumor was pure oligodendroglioma in five cases, four were anaplastic and one was low grade; two patients had mixed oligoastrocytomas, one high grade and one low grade. Anaplastic features included endothelial proliferation and high mitotic index (range 7-33/10 HPF) in five cases, focal endothelial proliferation with a mitotic index of 4/10 HPF in one case and necrosis with pseudopalisading in two. Both mixed gliomas had an oligodendroglioma-dominant histological appearance. Co-deletion of chromosomes $1 \mathrm{p}$ and $19 \mathrm{q}$ was detected in six out of seven primary tumors; the low grade oligoastrocytoma had intact $1 p$ and $19 q$ alleles. From the additional 138 cases diagnosed in the same period genetic analysis was available in 92 cases $(67 \%)$ and co-deletion of $1 p$ and $19 q$ was observed in $52(56 \%)$. Table 1 also summarizes the pathological, molecular genetic and clinical features of these cases including, age of the patient at initial brain tumor diagnosis, sex of the patient, treatment prescribed for the initial tumor, duration of tumor control following initial treatment and pathological features of the tumor at first relapse. Of note, most patients were male $(n=6)$, most were young (median age, 41; range, 28-50 years), most had a good performance status at initial diagnosis (median KPS, 90; range, 70-100) and most enjoyed a long progression-free interval between initial treatment and first recurrence (median, 41 months; range, 19-127 months). All tumors except one recurred in the brain and were re-resected; in each instance, the intracerebral recurrence had an oligodendroglial appearance and was high-grade. The single low-grade case recurred 10.5 years after initial resection. The recurrent tumor contained frequent mitoses and endothelial proliferation. In one case, the tumor relapsed in the leptomeninges without evidence of recurrence in the brain parenchyma (Table 1, case 6). Despite the eventual emergence of meningeal gliomatosis in these cases, invasion of leptomeninges by the primary oligodendroglial tumor was not evident in any of the pathological specimens examined. Of note, however, at initial or local recurrence resection, the lateral ventricle was penetrated in two cases (cases 1 and 3 ).

The initial management of these patients differed: two patients with anaplastic tumors, one of which was an oligoastrocytoma, had radiotherapy and adjuvant chemotherapy; one patient with a pure anaplastic oligodendroglioma had adjuvant chemotherapy only; and four patients, two with anaplastic oligodendrogliomas and the two patients with the low grade tumors, were observed initially and had no immediate post-operative treatment. Ordinarily, observation would be an unusual recommendation for patients with anaplastic gliomas, but this approach to management occurred in two instances because these tumors were initially interpreted to be low grade. Only when reviewed for the purposes of this study were the cases classified as anaplastic oligodendrogliomas.

Diagnosis and treatment of leptomeningeal disease: As summarized in Table 2, LMD was diagnosed approximately six years after the initial diagnosis of the primary tumor (median, 76 months; range, 19-151 months) and approximately two years after the first recurrence of the oligodendroglioma (median, 28 months; range, 0-36 months). At the time of diagnosis of LMD most patients had deteriorated neurologically (median KPS, 60; 
Table 1: Patient characteristics at initial diagnosis of brain tumor and first recurrence

\begin{tabular}{|c|c|c|c|c|c|c|c|c|}
\hline Patient \# & Gender & $\begin{array}{l}\text { Age } \\
\text { (years) }\end{array}$ & KPS & $\begin{array}{l}\text { Initial Pathology and } \\
\text { Genetics }\end{array}$ & Initial Treatment & $\begin{array}{l}\text { Time until first } \\
\text { recurrence } \\
\text { (months) }\end{array}$ & $\begin{array}{l}\text { Pathology at } \\
\text { recurrence }\end{array}$ & Treatment at recurrence \\
\hline 1 & M & 28 & 90 & $\begin{array}{l}\text { Oligo III } \\
\text { 1p19q deletions }\end{array}$ & GTR RT & 30 & Oligo III & PCV $x 6$ \\
\hline 2 & M & 42 & 70 & $\begin{array}{l}\text { Oligo II } \\
1 \mathrm{p} 19 \mathrm{q} \text { deletions }\end{array}$ & Biopsy & 127 & Oligo III & RT, TMZ x 4 \\
\hline 3 & M & 39 & 90 & $\begin{array}{l}\text { Oligo III } \\
\text { 1p19q deletions }\end{array}$ & STR PCV x 6 & 60 & Oligo III & RT \\
\hline 4 & M & 41 & 100 & $\begin{array}{l}\text { Oligo III } \\
\text { 1p19q deletions }\end{array}$ & STR & 40 & Oligo III & RT, PCV x 5 \\
\hline 5 & M & 45 & 90 & $\begin{array}{l}\text { Oligo III } \\
1 \text { p19q deletions }\end{array}$ & STR & 54 & Oligo III & $\begin{array}{l}\text { RT } \\
\text { PCV x } 4 \\
\text { TMZ x } 10\end{array}$ \\
\hline 6 & $\mathrm{~F}$ & 50 & 70 & $\begin{array}{l}\text { Mixed OA III 1p19q } \\
\text { deletions }\end{array}$ & $\begin{array}{l}\text { STR RT + TMZ } \\
\text { TMZ x } 6\end{array}$ & 19 & N/A & N/A \\
\hline 7 & M & 33 & 90 & $\begin{array}{l}\text { Mixed OA II } \\
\text { No deletions }\end{array}$ & STR & 41 & Mixed OA III & RT \\
\hline
\end{tabular}

KPS: Karnofsky Performance Score; M: male; F: female; N/A: Not applicable; Oligo: pure oligodendroglioma; OA: oligo-astrocytoma; GTR: gross total resection; Bx: biopsy; STR: subtotal resection; CT: chemotherapy; RT radiotherapy; PCV: procarbazine, CCNU, vincristine; TMZ: temozolomide

Table 2: Patient characteristics when leptomeningeal disease (LMD) was diagnosed

\begin{tabular}{|c|c|c|c|c|c|c|c|c|}
\hline Patient \# & $\begin{array}{l}\text { Time until LMD } \\
\text { from diagnosis } \\
\text { (months) }\end{array}$ & $\begin{array}{l}\text { Time until LMD } \\
\text { from recurrence } \\
\text { (months) }\end{array}$ & KPS & $\begin{array}{l}\text { Diagnosis of } \\
\text { LMD }\end{array}$ & Treatment of $L M D$ & Patient Status & $\begin{array}{l}\text { Survival from } \\
\text { diagnosis } \\
\text { (months) }\end{array}$ & $\begin{array}{l}\text { Survival } \\
\text { from LMD } \\
\text { (months) }\end{array}$ \\
\hline 1 & 66 & 35 months $/ 1^{\text {st }}$ & 30 & $\begin{array}{l}\text { Clinical } \\
\text { CSF cyt }\end{array}$ & $\begin{array}{l}\text { OR\# 3: Oligo III - IT TT x } 11 \\
\text { Carboplatin+ VP16 x } 6 \\
\text { OR\# 4: Oligo III } \quad \text { IT TT + Chl x } 16 \\
\text { VP16 + TMX x } 9 \text { TMZ x } 4 \text { BCNU x } 3\end{array}$ & $\mathrm{D}$ & 104 & 38 \\
\hline 2 & 151 & 24 months $/ 1^{\text {st }}$ & 50 & $\begin{array}{l}\text { Clinical } \\
\text { MRI }\end{array}$ & Palliative care. & $\mathrm{D}$ & 183 & 32 \\
\hline 3 & 96 & 36 months / $1^{\text {st }}$ & 90 & $\begin{array}{l}\text { Clinical } \\
\text { MRI }\end{array}$ & $\begin{array}{l}\text { TMZ x } 1 \quad \text { IT TT x } 13 \\
\text { CSpRT } 5580 \text { cGy } \\
\text { IT Mtx x } 1\end{array}$ & $\mathrm{D}$ & 127 & 31 \\
\hline 4 & 64 & 20 months $/ 1^{\text {st }}$ & 60 & $\begin{array}{l}\text { Clinical } \\
\text { MRI }\end{array}$ & $\begin{array}{l}\text { TMZ x } 1 \\
\text { IT TT } \times 10\end{array}$ & $\mathrm{D}$ & 107 & 43 \\
\hline 5 & 77 & 23 months $/ 1^{\text {st }}$ & 80 & $\begin{array}{l}\text { Clinical } \\
\text { MRI }\end{array}$ & Carboplatin + TMX x 1 & $\mathrm{D}$ & 87 & 10 \\
\hline 6 & 19 & At $1^{\text {st }}$ recurrence & 90 & $\begin{array}{l}\text { Clinical } \\
\text { MRI }\end{array}$ & $\mathrm{TMZ} *$ & A & 19 & N/A* \\
\hline 7 & 76 & 35 months $/ 1^{\text {st }}$ & 50 & $\begin{array}{l}\text { Clinical } \\
\text { MRI }\end{array}$ & Palliative care. & $\mathrm{D}$ & 78 & 2 \\
\hline
\end{tabular}

LMD: Leptomeningeal disease; RT: radiotherapy; KPS: Karnofsky Performance Score; N/A: not available; MRI: Magnetic Resonance Imaging; CSF cyt: cerebrospinal fluid cythology; IT: intrathecal; OR: surgery; D: deceased; A: Alive; PCV: procarbazine, CCNU, vincristine; TMZ: temozolomide; TT: thiotepa; Chl: chlorambucil ; TMX: tamoxifen; CSpRT: Craniospinal RT; *: this patient has just been diagnosed with LMD without local recurrence and started treatment. 
range, 30-90). The diagnosis of LMD was suspected clinically and confirmed by MRI in all cases. Patients with only supratentorial involvement had multiple sub-ependymal or subarachnoid nodules clearly separated from the primary tumor location. One patient with a normal MRI had a positive CSF cytology. The CSF was sampled in two others (two and three times, respectively) and was negative for malignant cells. In four patients, the diagnosis of LMD was based on clinical and radiographic findings only; in these cases, either the patient refused a spinal tap or CSF sampling was judged to be unsafe. In one patient, intraventricular spread was confirmed by FDG Positron Emission Tomography (PET; Figure). Based on clinical and radiographic features, the major sites of LMD were the lateral ventricles in four patients, the 4th ventricle in two, the spinal subarachnoid space in two and the basal meninges and brain stem in one. Both patients with spinal leptomeningeal spread complained of back pain. Those with meningeal disease in the posterior fossa presented nausea, vomiting and dizziness. The clinical manifestations associated with subependymal spread were less specific but included a general decline in cognitive functioning.

The management of LMD differed widely. Intrathecal chemotherapy with thiotepa was the first therapeutic intervention in three cases (range, 10-27 cycles). Different types of systemic chemotherapy were also prescribed (Table 2). One of two patients with spinal involvement received local external beam
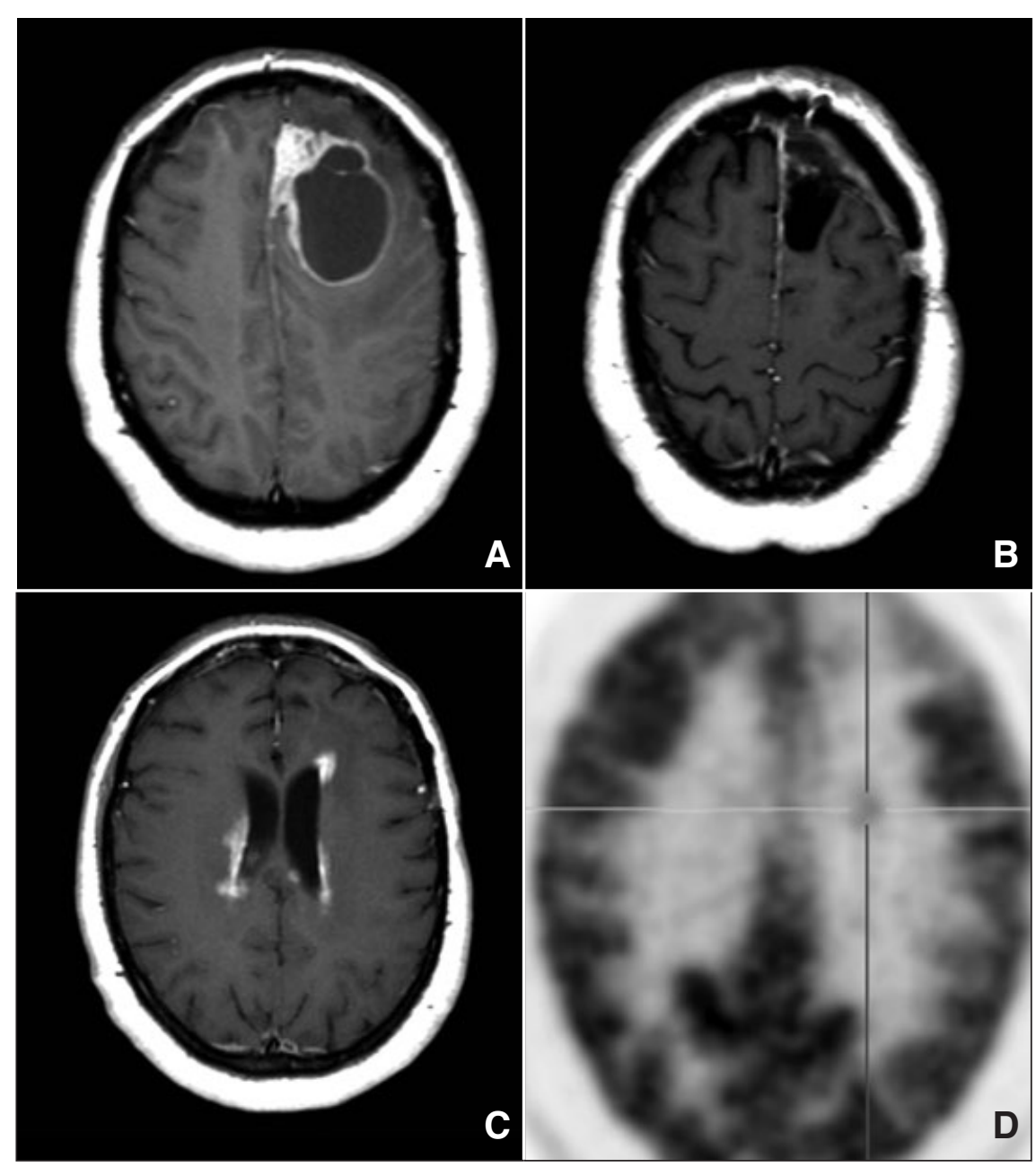

Figure: Patient \#6 presented with seizures. Axial post-gadolinium T1W images show the mixed cystic/solid left frontal lobe anaplastic oligodendroglioma (A) with $1 p$ and $19 q$ deletions. A gross total resection was performed, with concurrent radiotherapy and chemotherapy followed by six cycles of adjuvant chemotherapy. Nineteen months later, without evidence of local tumor recurrence $(B)$, subependymal tumor spread was evident $(C)$ along with clinical evidence of spinal involvement (MR imaging negative). The PET scan revealed metastatic subependymal tumor spread with low avidity for $F D G(D)$. 
radiotherapy. The CSF from the patient who had positive cytology at diagnosis of LMD was never free from neoplastic cells despite intrathecal treatment. In the final stages when the patient was treated exclusively with systemic therapy, CSF was not sampled. After suspending all treatment, two patients, both with LMD secondary to oligodendrogliomas harboring a codeletion of $1 \mathrm{p}$ and $19 \mathrm{q}$, remained stable clinically for 20 and 35 months, respectively. Six of these seven patients have died and although in some cases a slow progression of LMD was evident, the cause of death was related to further progression of the recurrent intracerebral tumor at the initial location. Autopsies were not performed on these cases. Overall, these patients lived approximately eight years from initial brain tumor diagnosis (median, 104 months; range, 19-183 months) and survived nearly three years from the diagnosis of leptomeningeal metastasis (median, 32 months; range, 2-43 months).

\section{Discussion}

Oligodendrogliomas comprise approximately $5 \%$ of primary brain tumors and $15 \%$ of gliomas. ${ }^{4}$ The incidence of oligodendroglial tumors may be increasing although this likely reflects earlier diagnosis by MRI and liberalization of the diagnostic criteria for oligodendroglioma to include many mixed oligoastrocytomas. This trend to liberalization of the histological criteria may have been motivated by the concern that a treatment-sensitive tumor not be overlooked inadvertently. ${ }^{5}$ Balancing this trend to "over-diagnosis" has been the introduction of molecular diagnostics to neuro-oncology and the recognition of the clinical relevance of $1 p$ and $19 q$ loss in oligodendroglial neoplasms. Co-deletion of chromosomes $1 \mathrm{p}$ and $19 q$ (likely a manifestation of a $1 q / 19 p$ unbalanced translocation) is associated with a better prognosis. ${ }^{6-8}$ and response to treatment ${ }^{9-11}$ Patients harboring a tumor with a codeletion have a median survival in excess of seven years versus less than three years in those with intact alleles. It is in this context that some patients develop leptomeningeal metastasis.

Leptomeningeal disease is an uncommon complication of oligodendroglioma; it has been reported to occur in $1-2 \%$ of cases. This may be a falsely low rate, however, because CSF analysis and imaging of the spine are not standard procedures in the initial evaluation and follow-up of patients with oligodendroglial tumors. In this study, nearly $5 \%$ of patients with oligodendrogliomas developed LMD, perhaps reflecting our longstanding interest in this disease and tendency, therefore, to investigate even minor clinical symptoms thoroughly with detailed neuro-imaging. A high rate of LMD should come as no surprise in this disease given long survival times, aggressive treatment and the high rate of microscopic invasion of the leptomeninges which is seen in up to $14 \%$ of oligodendrogliomas. , $^{12-15}$

In our series of seven cases, two clinical features deserve further comment. First, as expected, LMD surfaced in the context of advanced disease, appearing many months after recurrence of the primary tumor. The single exception was a patient who developed LMD as the first site of relapse. All tumors that spread to the leptomeninges had previously been irradiated. Cancers that relapse after radiotherapy or radiotherapy and chemotherapy typically harbor a broader spectrum of genetic alterations and are usually more aggressive clinically. Such aggressiveness might be manifest in LMD. Second, at initial diagnosis, all patients that subsequently developed LMD had very favorable prognostic characteristics (e.g. young age, excellent KPS, favorable genetics, etc.). Median overall survival of our patients was eight years. This suggests that log survival contributed to the development of LMD in this group of cases. There is a precedence for this link in other cancers. For example, the successful treatment of HER2positive breast cancers and of small cell lung cancer has been associated with unusual patterns of recurrence in long-term survivors ${ }^{16-18}$

The small number of cases in this series precludes statistical analysis of the association between the co-deletion of chromosomes $1 p$ and $19 q$ and the occurrence of LMD. Similarly, until the molecular consequences of $1 p$ and $19 q$ codeletion are fully understood, it is not be possible to know whether co-deletion of $1 p$ and $19 q$ (i.e., "Jenkins chromosome") causes an invasive tumor. Other mechanisms such as breaching of the ventricle at the time of surgery may have caused LMD in two patients.

Moreover, we are uncertain whether patients with leptomeningeal oligodendroglioma benefit from contemporary therapies such as involved field radiotherapy, intrathecal chemotherapy, or systemic chemotherapy. Although our patients tolerated various therapies, including intrathecal thiotepa, it is unclear whether or not they lived longer or better as a result. We did not observe a complete or major partial radiographic response to any therapy directed at the LMD. We now avoid potentially toxic therapies in these patients with longer survivals and use single agent systemic chemotherapy with temozolomide, a DNA methylating agent that penetrates the CNS and is well tolerated.

\section{REFERENCES}

1. Bordignon K, Coelho M, Ramina R, Sousa de Meneses M, Zazula A, Morato L. Patterns of neuroaxis dissemination of gliomas: suggestion of a classification based on magnetic resonance imaging findings. Surg Neurol. 2006;65:472-7.

2. Ng HK, Sun DTF, Poon WS. Anaplastic oligodendroglioma with drop metastasis to the spinal cord. Clin Neurol Neurosurg. 2002;104:383-6.

3. Giannini C, Scheithauer BW, Weaver AL, Burger PC, Kros JM, Mork S, et al. Oligodendrogliomas: reproducibility and prognostic value of histologic diagnosis and grading. J Neuropathol Exp Neurol. 2001;60:248-62.

4. Engelhard HH, Stelea A, Mundt A. Oligodendroglioma and anaplastic oligodendroglioma: clinical features, treatment and prognosis. Surg Neurol. 2003;60:443-56.

5. Jukich PJ, McCarthy BJ, Surawicz TS, Freels S, Davis FG. Trends in incidence of primary brain tumors in the United States, 19851994. Neuro-oncol. 2001;3:141-51.

6. Cairncross G, Berkey B, Shaw E, Jenkins R, Scheithauer B, Brachman D, et al. Phase III trial of chemotherapy plus radiotherapy compared with radiotherapy alone for pure and mixed anaplastic oligodendroglioma: Intergroup Radiation Therapy Oncology Group Trial 9402. J Clin Oncol. 2006;24:2707-14.

7. van den Bent MJ, Carpentier AF, Brandes AA, Sanson M, Taphoorn MJ, Bernsen HJ, et al. Adjuvant procarbazine, lomustine, and vincristine improves progression-free survival but not overall survival in newly diagnosed anaplastic oligodendrogliomas and oligoastrocytomas: a randomized European Organization for Research and Treatment of Cancer phase III trial. J Clin Oncol. 2006;24:2715-22. 
8. Jenkins RB, Blair H, Ballman KV, Giannini C, Arusell RM, Law $\mathrm{M}$, et al. A $\mathrm{t}(1 ; 19)(\mathrm{q} 10 ; \mathrm{p} 10)$ mediates the combined deletions of $1 \mathrm{p}$ and $19 \mathrm{q}$ and predicts a better prognosis of patients with oligodendroglioma. Cancer Res. 2006;66:9852-61.

9. Cairncross JG, Ueki K, Zlatescu MC, Lisle DK, Finkelstein DM, Hammond RR, et al. Specific genetic predictors of chemotherapeutic response and survival in patients with anaplastic oligodendrogliomas. J Natl Cancer Inst. 1998;90:1473-9.

10. Bauman GS, Ino Y, Ueki K, Zlatescu MC, Fisher BJ, Macdonald $\mathrm{DR}$, et al. Allelic loss of chromosome 1p and radiotherapy plus chemotherapy in patients with oligodendrogliomas. Int J Radiat Oncol Biol Phys. 2000;48(3):825-30.

11. Ino Y, Betensky RA, Zlatescu MC, Sasaki H, Macdonald DR, Stemmer-Rachamimov AO, et al. Molecular subtypes of anaplastic oligodendroglioma: implications for patient management at diagnosis. Clin Cancer Res. 2001;7:839-45.

12. Vandenberg SR, Lopes MBS. Classification. In: Berger MS, Wilson CB, editors. The Gliomas. Philadelphia: WB Saunders; 1999: p. 181-84.
13. Reifenberger G, Kros JM, Burger PC, Louis DN, Colins VP. Oligodendroglioma. In: Kleihues P, Cavenee WK, editors. Pathology and genetics of tumours of the nervous system. 2nd ed. Lyon, France: IARC Press; 2000. p. 56-61.

14. Engelhard HH. Current diagnosis and treatment of oligodendroglioma. Neurosurg Focus. 2002;12:1-7.

15. Engelhard HH, Stelea A, Cochran EJ. Oligodendroglioma: pathology and molecular biology. Surg Neurol. 2002;57:111-7.

16. Seute T, Leffers P, Ten Velde G, Twijnstra A. Leptomeningeal metastases from small cell lung carcinoma frequencies and survival. Cancer. 2005;104:1700-5.

17. Yau T, Swanton C, Chua S, Sue A, Walsh G, Rostom A, et al. Incidence, pattern and timing of brain metastases among patients with advanced breast cancer treated with trastuzumab. Acta Oncol. 2006;45:196-201.

18. Puente Vazquez J, Lopez-Tarruella Cobo S, Garcia-Saenz JA, Casado Herraez A, Moreno Anton F, Sampedro Gimeno T, et al. Brain metastases in metastatic breast cancer patients receiving trastuzumab-based therapies. Clin Transl Oncol. 2006;8:50-3. 